\section{Commentary: Not every untreated acute type A dissection will rupture, but every untreated malperfusion will result in death}

\author{
Bo Yang, MD, $\mathrm{PhD}$
}

In 1994, at the University of Michigan, Drs Michael Deeb (cardiac surgeon) and David Williams (interventional radiologist) advocated for a new concept for treating patients with acute type A aortic dissection (ATAAD) and malperfusion syndrome (MPS). The idea was to treat the malperfusion first with an endovascular approach followed by delayed open aortic repair once the patients recovered from MPS. These early results were presented at the 33rd annual meeting of the Society of Thoracic Surgeons in 1997. ${ }^{1}$ Dr Deeb was criticized by renowned cardiac surgeons as being immoral for delaying open aortic repair because some patients died from aortic rupture during the recovery from MPS. Twenty-six years have now passed. More and more surgeons have realized the operative mortality can be as high as $60 \%$ to $70 \%$ in patients with ATAAD and MPS, more specifically mesenteric MPS, and an alternative strategy is needed. Surgeons have started adopting the strategy of treating the malperfusion first followed by delayed open repair with excellent outcomes, ${ }^{2,3}$ including a case report published in the September 2020 issue of JTCVS Techniques. ${ }^{4}$

The indication for endovascular treatment should be MPS, not just malperfusion. The difference between malperfusion and MPS is similar to the difference between bacteremia and sepsis, or HIV and AIDS. Malperfusion is inadequate blood flow to the end organs. Malperfusion syndrome is the consequence of prolonged malperfusion, including cell, tissue, and organ necrosis and dysfunction. Malperfusion can be diagnosed via clinical examination

From the Department of Cardiac Surgery, Michigan Medicine, Ann Arbor, Mich. Disclosures: The author reported no conflicts of interest.

The Journal policy requires editors and reviewers to disclose conflicts of interest and to decline handling or reviewing manuscripts for which they may have a conflict of interest. The editors and reviewers of this article have no conflicts of interest.

Received for publication Aug 19, 2020; revisions received Aug 19, 2020; accepted for publication Aug 21, 2020; available ahead of print Sept 2, 2020.

Address for reprints: Bo Yang, MD, PhD, 1500 East Medical Center Dr, 5155 Frankel Cardiovascular Center, Ann Arbor, MI 48109 (E-mail: boya@med.umich.edu). JTCVS Techniques 2020;4:79-80

2666-2507

Copyright (C) 2020 The Authors. Published by Elsevier Inc. on behalf of The American Association for Thoracic Surgery. This is an open access article under the CC BY-NCND license (http://creativecommons.org/licenses/by-nc-nd/4.0/).

https://doi.org/10.1016/j.xjtc.2020.08.055

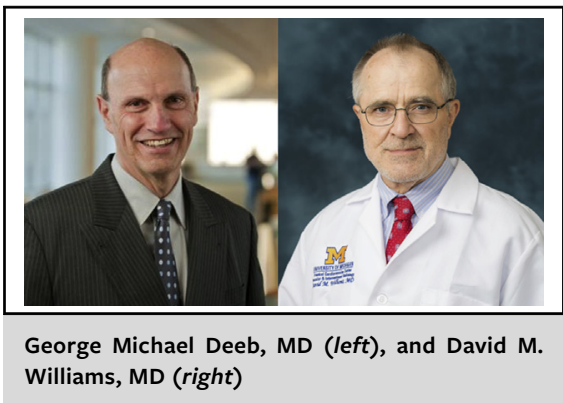

CENTRAL MESSAGE

Like many successful stories of innovation, persistence and collaboration win in the end.

(absent pulse) and imaging studies (such as computed tomography angiogram or arteriography with manometry). Malperfusion syndrome can be diagnosed by clinical assessment, including symptoms (such as abdominal pain), physical examination (peritoneal signs), and laboratory tests (serum lactate, arterial blood gas). In the early stages of malperfusion, if the patients have not yet developed MPS, the treatment is immediate open central aortic repair. However, when patients have already developed MPS, as described in the case report in this issue ${ }^{4}$ the operative mortality of central aortic repair can be $60 \%$ to $70 \%$. A better strategy may be to resolve the malperfusion first with an endovascular approach, wait for the patient to recover from MPS (acidosis, acute respiratory distress syndrome, resection of necrotic bowel), and then perform the open central aortic repair.

There are 2 main approaches to resolving malperfusion of the aortic branch vessels. One is fenestration and stenting of the aorta and its branch vessels. ${ }^{5,6}$ Fenestration and aortic true lumen stenting create a passageway for blood flow between the false and true lumen of the aorta. Placing bare metal stents in the true lumen of the aorta and its branch vessels when there is a static malperfusion in the branch vessels prevents collapse of the true lumen and recurrent malperfusion. This technique can resolve both dynamic and static malperfusion. The second technique is to place a stent graft (thoracic endovascular aortic repair) in the true lumen of the descending aorta to keep the true lumen open. ${ }^{2,3}$ This technique can reliably treat only dynamic malperfusion, such as in this case report. ${ }^{4}$ It is not uncommon to see the distal aorta collapse after stent grafts are placed in the true lumen of the descending thoracic aorta, probably secondary to limited re-entry tears in the distal false lumen. This 
phenomenon also occurs when fenestration and stenting is used. The treatment for the collapsing of the true lumen of the distal aorta is distal aorta fenestration with or without further stenting with a bare metal stent in the true lumen. The authors did an excellent job with a Zenith stent (Cook) to keep the true lumen of the abdominal aorta open and resolved the dynamic malperfusion of the visceral branches of the aorta. ${ }^{4}$ If there is static malperfusion of the visceral branches due to dissection extending into the branches and thrombosis of the false lumen of the branch vessel, TEVAR by itself cannot resolve the static malperfusion; the static malperfusion requires additional branch vessel stenting. Presence of static malperfusion is established by manometry comparing aortic root pressure with distal branch artery pressure. Confirmation of adequate treatment of static obstruction involves demonstration of no significant gradient between aortic root and distal branch artery pressure. Zenith stents, in this case, could complicate the stenting of visceral branch vessels. Another advantage of fenestration and stenting is the very low risk of false lumen thrombosis and subsequent spinal cord ischemic injury.

When patients are awaiting open aortic repair, there is always a risk of aortic rupture. Surgeons need to become comfortable with the medical management of acute type A aortic dissection. In our experience, with more aggressive blood pressure control (systolic $<110 \mathrm{~mm} \mathrm{Hg}$ ), avoidance of agitation, and early repair as soon as the patient can tolerate cardiopulmonary bypass and hypothermic circulatory arrest, the risk of rupture decreased significantly in the last decade $(4 \%$ in patients with all
MPS, and $0 \%$ in patients with mesenteric MPS, which is much better than the operative mortality in this patient population). ${ }^{5,6}$

It took 2 and a half decades of persistent long-term follow-up and treatment strategy improvement from birth of the concept of treating malperfusion first in patients with ATAAD with MPS to develop a mature strategy, and for surgeons to adopt this strategy. It is a familiar theme: in many successful stories of innovation, persistence and collaboration win in the end.

\section{References}

1. Deeb GM, Williams DM, Bolling SF, Quint LE, Monaghan H, Sievers J, et al. Surgical delay for acute type A dissection with malperfusion. Ann Thorac Surg. 1997; 64:1669-75; discussion 1675-7.

2. Leshnower BG, Keeling WB, Duwayri YM, Jordan WD Jr, Chen EP. The "thoracic endovascular aortic repair-first" strategy for acute type A dissection with mesenteric malperfusion: initial results compared with conventional algorithms. J Thorac Cardiovasc Surg. 2019;158:1516-24.

3. Midulla M, Renaud A, Martinelli T, Koussa M, Mounier-Vehier C, Prat A, et al. Endovascular fenestration in aortic dissection with acute malperfusion syndrome: immediate and late follow-up. J Thorac Cardiovasc Surg. 2011;142:66-72.

4. Preventza O, Olutoye OO, Chatterjee S, Huu AL, Coselli JS. Provisional extension to induce complete attachment of an endovascular repair for acute type A aortic dissection with visceral malperfusion. J Thorac Cardiovasc Surg Tech. 2020; 3C:61-3.

5. Yang B, Rosati CM, Norton EL, Kim KM, Khaja MS, Dasika N, et al. Endovascular fenestration/stenting first followed by delayed open aortic repair for acute type A aortic dissection with malperfusion syndrome. Circulation. 2018;138: 2091-103.

6. Yang B, Norton EL, Rosati CM, Wu X, Kim KM, Khaja MS, et al. Managing patients with acute type A aortic dissection and mesenteric malperfusion syndrome: 20-year experience. J Thorac Cardiovasc Surg. 2019;158:675-87.e4.

7. Norton EL, Williams DM, Kim KM, Khaja MS, Wu X, Patel HJ, et al. Management of acute type B aortic dissection with malperfusion via endovascular fenestration/stenting. J Thorac Cardiovasc Surg. September 30, 2019 [Epub ahead of print]. 